\title{
A Comparative Study Between the Climate Response Strategies and Thermal Comfort of a Traditional and Contemporary Houses in KRG: Erbil
}

\author{
Diler Haji Morad \\ Architecture Engineering department \\ College of Engineering \\ University of Duhok, Iraq \\ Diler.morad@uod.ac
}

Abstract: The hot and dry climate conditions in Erbil city has a main effect on the energy consumption and thermal performance of the house. In the last decade, residential sector in Kurdistan region government has consumed about 50\% of total energy consumption. The contemporary dwelling did not consider climate consideration therefore; there was difficulty in achieving or obtaining thermal comfort conditions, without using electrical or mechanical devices like airconditioning. In contrast, traditional houses carefully and effectively designed with climate conditions. In the present study, in order to determine suitable architectural strategy that may be benefit in future housing designs, the climate response strategies and thermal comfort examined in both traditional and contemporary houses in Erbil city and evaluated in terms of building form, orientation, occupancy migration, plan arrangement, window, ventilation, shading, Vegetation, water bodies building materials and Urban Fabric. At the end of this study, a simplified evaluation and comparison between contemporary and traditional house are given.

Keywords: Climate condition, Thermal comfort, evaluation, comparison, Traditional and Contemporary houses

\section{INTRODUCTION}

Climate has a main impact on the thermal performance and energy consumption of houses especially in countries with hot and dry climates such as Kurdistan region government, where people facing different problems, which related to climate especially in contemporary housing. In the last decade, residential sector in Kurdistan region government have consumed about $50 \%$ of total energy consumption (fig.1) [1] . Erbil city offers a good case of a contrast between contemporary and traditional houses. Although Erbil is one of the oldest cities in Kurdistan region, there houses remain and still occupied by citizens. This offers an opportunity to compare the traditional city with that contemporary city in the performance of architecture in order to achieve the best techniques and methods to maintain thermal comfort in hot and dry climates. Therefore, for an understanding of the thermal performance of both contemporary and traditional houses, various aspects are necessary such as architectural design, occupancy patterns, planning and constructional methods and materials. The present study aimed at finding the main climate response strategies to achieve thermal comfort for future houses.

\author{
Serbest Khalil Ismail \\ Architecture Engineering department \\ College of Engineering \\ University of Duhok, Iraq \\ Serbest.ismael@uod.ac
}

Figure 1 Electricity

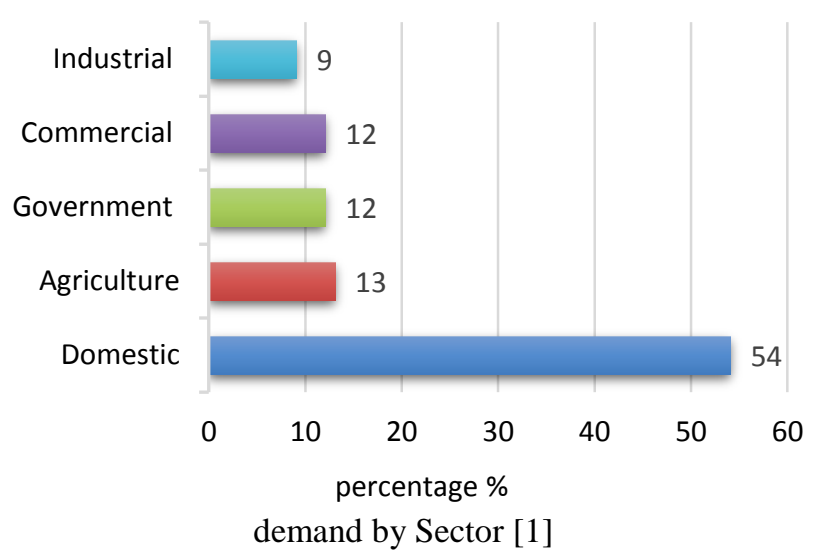

2. LITERATURE REVIEW

According to Hasan Fathy the traditional building is related to the majority cultures of the society, and work as symbols of identity as well as reflect the environmental specification of that region [2].

In the 18th century, research about traditional architectures had started, the studies in that time had different feature some considered it as national architecture element. In the 20th century, architects began to bring traditional buildings to the field and theory of architecture [2].

The village of new Gournah, designed by Hasan Fathy in 1946, is the first project attempt to implement traditional architecture in to architectural field. He uses traditional Egyptian design strategy such as mud bricks in its construction, available materials in the region and traditional Nubian techniques in the houses [2].

In 2005, Nazife Ozay published article about the comparative study between tradition and contemporary houses in Northern Cyprus regarding of climatically responsive in term of the form, materials, windows and orientation of the building, and she conclude that the tradition climate strategy response has been ignored in the new building [3].

Another important research published by Boqvist et al in 2012, about the comparison between passive house construction and traditional building construction in Sweden in term of construction thermal performance, climatic response and building efficiency [4]. Furthermore, there are many studies have been done in many countries about these issues.

Until now there is no studies and measurement data 
about the comparison between traditional and contemporary houses in Kurdistan region. But there are many study about traditional building in Kurdistan region. Therefore, this paper will be the basic for development of studies about this subject.

\section{ERBIL CLIMATE}

Erbil city is located to the north of Iraq at Kurdistan government region between (36.19) Latitude and (44.009) Longitude. The Erbil's climate is classified as semi-arid continental and is characterized by large differences in temperature between summer and winter and between day and night with extreme conditions. Summer season (Jun, July, August and September) is very hot and dry and the hottest average temperature is about $43 \mathrm{C}$ and in the hottest day the temperature rises above 48C. While the winter season (November, December, January and February) is cold and wet, the lowest average temperature about $2 \mathrm{C}$ and in the lowest day the temperature declines below $-5 \mathrm{Cm}$, with the total average rainfall about 300-400 millimeters annually [5]. The humidity is high in winter by average $80 \%$ and low in summer by average $20 \%$. The annual wide speed relatively slow about 3-5 (fig.2) [6].

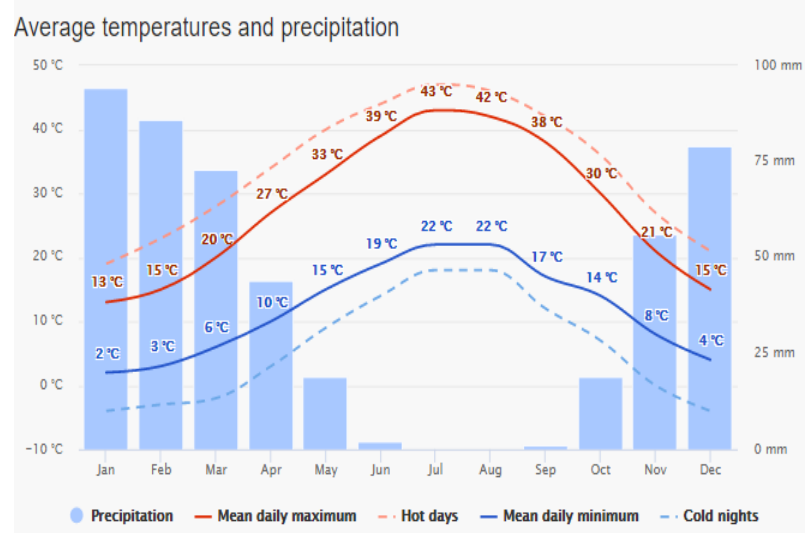

Figure 2 Erbil monthly average temperature and precipitation (www.accuweather.com)

\section{Macro \& Micro Climate Responsive DESIGN STRATEgIES IN TRADITIONAL BUILDINGS.}

Traditional buildings in Erbil were designed to withstand the sever climate conditions that surrounding them. The outcome was successful dwelling that stood the test of time for thousands of years to prove that responsive design strategies are effective for the buildings to combat and successfully respond to the environment condition surrounding it. The following are the main design strategies that have been used in traditional buildings [7]:

\subsection{Urban Fabric}

Erbil Traditional buildings got evolved within 7000 years ago. The Erbil Citadel has been influenced more with northern side of the neighboring cities in Turkey and Iran, on contrast to the form, where the design finds to be similar to the buildings in Baghdad. This is mainly because they were under the same climate and culture influence [8].

The Citadel is mainly occupied by traditional courtyard houses reached through a maze of narrow alleyways. The pedestrian alleyways, which ranged in width from one to two and half meters, entered throughout the Citadel in tree like pattern are a logical functional solution to the circulation. While allalleyways began naturally from the main-gate and spread in all directions. The gate allows only entry and exit for all residents of the city (fig.3A). They are narrow and deep (i.e. alleyways) to provide shading over the street and neighboring buildings that reduces the air temperature as well as it provides protection in the neighborhood from sand storms, as the high density of buildings will reduce the wind arrays [9].

Building in Citadel were grouped close together to shade each other from the sun of midday. The ratio between street width and building height created a protected area from the sun of hot summer months, and this making walking comfortable and allowing the populations to sit in the street (fig.3B) [10].

Ecological site planning allows suitable levels of solar radiation and natural day light in to each residence unit. Each housing unit will need a relatively unhindered southern exposure during the winter season, and the design of house itself will require to ensure that sun can enter into the inside of the house While the highest angle of summer sun is excluded to keep the house unit cool [9].

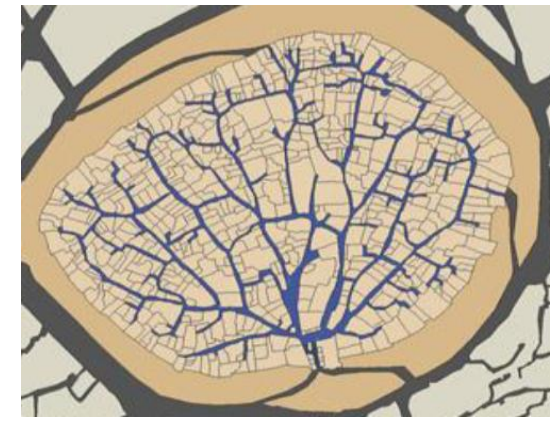

A- Site plan showing roads

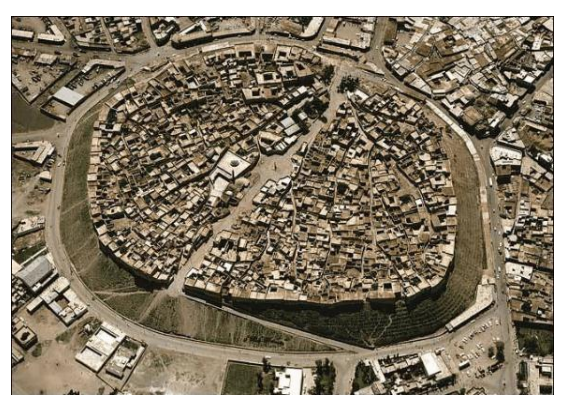

B-Aerial picture of residential building

Figure 2 Erbil Citadel A- Site plan showing roads B-Aerial picture of residential building (http://www.erbilcitadel.org) 


\subsection{Form and Orientation}

External envelop of the building is the most important layer that affects and controls the desirable wind exposer and solar access to moderate the heat loss and heat gain through the building.

Typical houses design in Erbil are constructed with the courtyards that are the center of the plans with restrictions given by the form of the land parcel. Usually the courtyards were planned to be geometric in form either rectangle or square with its long axis or perpendicular to the solar orientation. All the windows of the rooms in both stories are oriented towards the courtyard to allow for natural ventilation and breathing of the building (fig.4 A-B) [11]. Most houses are designed as two floors; the lower floor usually at one to one and half-meters under courtyard level. This floor is also accessed directly from the courtyard by relatively four or five steps. Semi basements always have vaultedroofs resting on thick brick piers. Usually ceilings are build up with two and half to three meters high with several windows facing the courtyard(fig.4D). The second level or the upper floor has a high ceiling, and lower windows to allow for cross ventilation and let more day light into the space [12].

These forms of the houses are known as introvert enclosure, shut off from its surrounding by solid and high walls to provide its occupants with privacy and block street noise. Hence, these spaces and rooms look indoors onto a secluded and private open space, the courtyard. Through which they receive daylight, natural ventilation, sunlight and have visual and physical communication from inside to outside(fig.4C) [13]. While Orientation is the logical response for climate, especially the orientation toward the south facing since it is the main source solar exposure and perhaps source for comfort or discomfort during respective season. Since Iraq is located in the northern hemisphere, The arrangement of space in the building is designed according to the sun path arches all over the south. Consequently, in indigenous houses, all the summer spaces are located in the southern part of the courtyard as well as all the openings of this part face north. In contrast, rooms used in the winter generally exist on the north side [7].

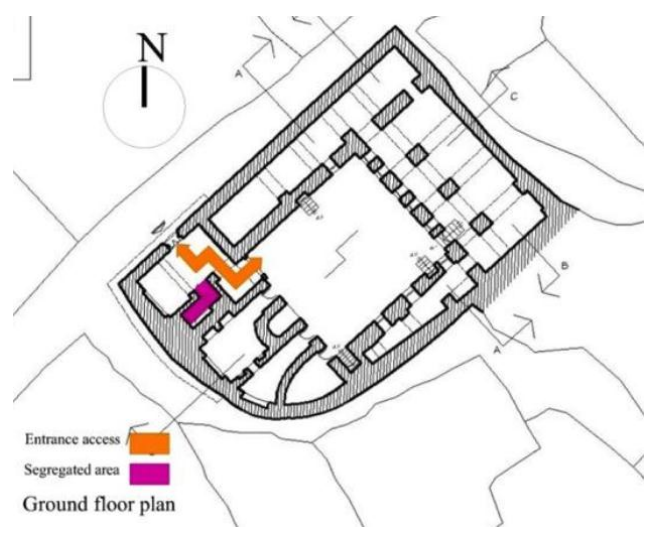

A- Ground Floor Plan
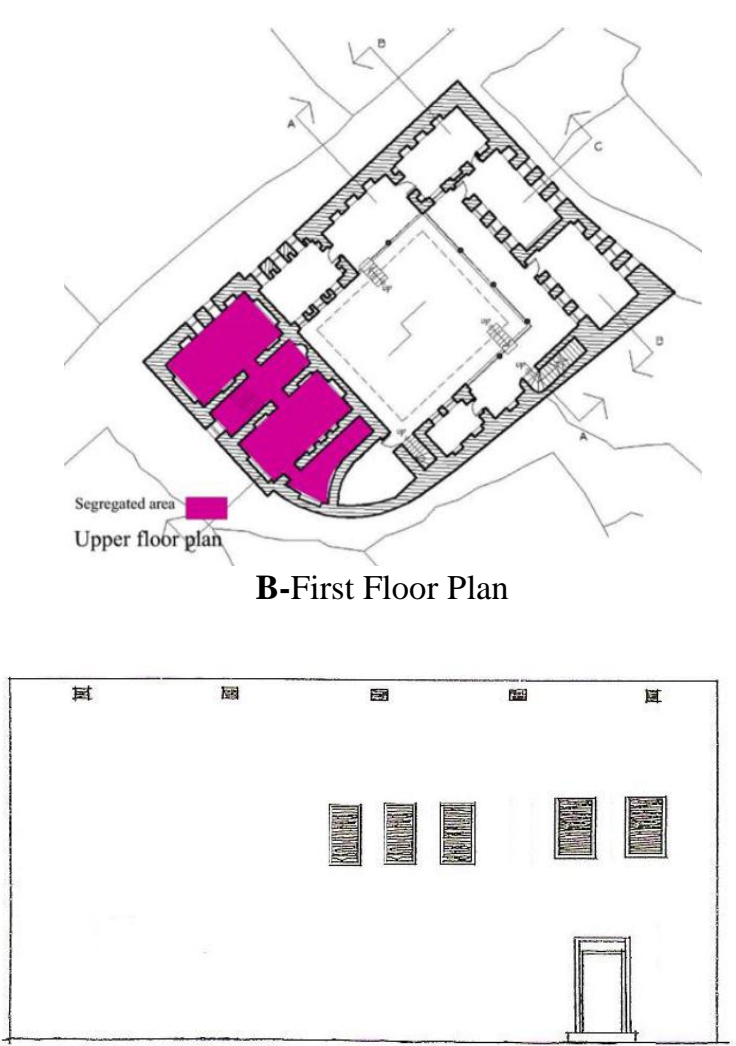

C- Elevation Plan

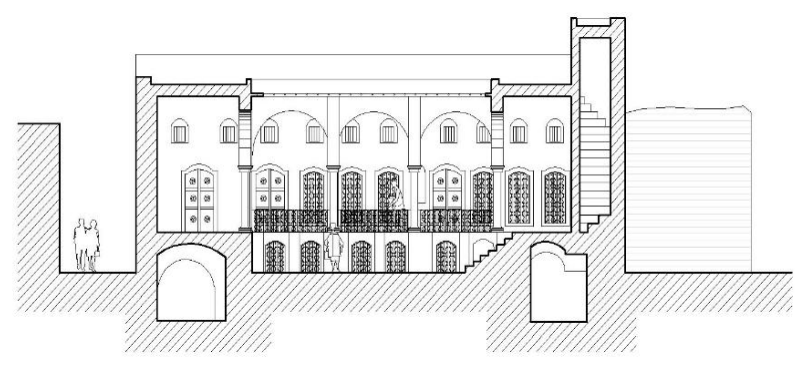

D- Section Plan

Figure 4 Erbil Citadel typical houses A- Ground Floor Plan B-First Floor Plan C- Elevation Plan D- Section Plan (http://www.erbilcitadel.org)

\subsection{Occupancy Migration- Plan Arrangement}

According to Warren and Al-Azzawi the rooms are used according to the time of the day or season, from the cellar to attic. The behavior patterns changed, in summer two periods of sleep were the rule; in the cellar during the afternoon and on the roof in the cool of the early hours. At other times of the year the day was un broken and the night was spent in a first floor room." Therefore, the colonnaded house are places of complex microclimates where each area is used to its best advantage and where the courtyard itself is a giant room, or acting as the hub of life in the building [14] [15]

Horizontal migration inside the houses of Erbil is a seasonal move between the rooms according to their orientations. In other words, in the wintertime, sun shine 
is desirable and occupants prefer to have the rooms with large windows that are south facing with low ceilings high to gain sun heat. In contrast, summer season it is desirable to have the rooms north facing north, usually are open with high ceilings to allow for cross ventilation will serve the best in Erbil [16].

The vertical migration is the greatest effective response to temperature change. Since the climate is at its peak, meaning the morning time is spent in the ground floor; the semi basement is used for the afternoon time when the heat is excessive. While at night, roof space is used for sleeping. This approach is based on cool sky radiation at night according to the fact that warm air rises whereas cool air is collected in low space [17].

\subsection{Windows, Ventilation and Shading.}

Ventilation is an essential factor of modifying the hot and dry climate. The courtyard response for the climate is highly effective, where the courtyard is collecting cool and dense air at night, and provides the surrounding rooms with cool air till well into the day. When the sun reaches the courtyard, the air is heated and convection currents rise and cross ventilation occurs, especially when the surrounding spaces have secondary ventilation sources from cool alleys and adjacent narrow [18]. In addition, the "Bad Geer" or wind towers is a remarkable ventilation device. It is tall narrow intakes open to the roof terrace; capturing the prevailing wind from North West in Kurdistan to catch clear and cool air to the below rooms. Through these rooms, the air passes in to the courtyard, feeding the convection cycle. Different levels receive independent wind scopes [19].

The difference of sun angles between summer and winter solstice gets higher the further south or north from the equator. Hence, November until March months, sun infiltrate deeper to ward south oriented rooms when warm is preferred, while from April until October months, shading devices are useful against direct sun. The outside shading elements on the facades has a minor role in the Erbil dwelling, While the houses are adjacent and introvert from three sides. However, the shadings are placed interior the house around the courtyard. The arcade and colonnade around the courtyard provides shading for the room around the court [20].

\subsection{Water Body and Vegetation.}

Water has a moderating effect on the air temperature of the micro-climate through Moisture Thermal Transfer relative to cooling a space, as dry, warm air passes past small droplets of water, the heat from the air transfers in to the water, making the air cooler. This facilitates evaporation of the water, which causes the water further cool. Water possesses very high thermal storage capacity; therefore, majority Erbil traditional building have fountains [21]. The design behind the idea is that water has the capability to moderate the air temperature in the surroundings and takes up heat from air through evaporation and causes significant drop of temperature [22].
Vegetation is an effective way of changing the temperature for better conditions by Evapotranspiration. Transpiration is a cluster of plants that creates the cooling effect of evaporation as air moves through or across then plants. The air is cooled as the plants remove heat to affect the evaporation state change. Furthermore, it provides shade to the house to decrease the intense solar exposure. Erbil traditional building used to have trees in the courtyard since all the windows are opened toward the courtyard [23].

\subsection{Building (construction) Materials.}

Building materials and construction techniques were developed, and adopted to protect the occupant from climatic factors and temperature range. The structure is baring wall system, the roof is constructed by wooden timber beam material with thickness about $20-25 \mathrm{~cm}$ and covered by mat with clay without finishing. the external and interior walls are built from mud and stone with thickness about $50-75 \mathrm{~cm}$. windows and doors made from wood and steel, Mass construction of traditional houses in Erbil use certain exterior materials whether it made of mud or stone that are well insulated to prolong and protect the house against the heat in the day time and delay the heat transmission to its thermal mass characteristic. Sometimes even storing the heat to protect itself for the chilly mornings [24] [25].

\section{Macro \& Micro Climate Responsive DESIGN STRATEgIES IN CONTEMPORARY BUILDINGS}

Contemporary house (modern house concept) in Erbil city is characterized and influenced by many different architectural styles and design like Western architecture that are unfamiliar to the area, without considering social life, the distinctive climatic conditions and the advantages of traditional architecture. This is mainly because of shortage of building regulations and economic aspect as well as lack of knowledge about the thermal-performance of modern materials and constructional methods [26]. Contemporary house has grown quickly because it is meet social and individual need for a social success symbol and traditional house is perceived to be undesirable and old.

\subsection{Urban Fabric}

New urban expansions and building were designed in the Erbil and applied without respect for characteristics of city, because urban planning codes adapted from Iraqi and foreign countries that are unrelated to the social life and cultural of the region. Therefore, the existent house did not have formal codes that led to the great diversity. Mainly, the urban planning of neighborhood characterized by main streets that have a rectilinear grid layout system as well as Secondary Street, and the blocks of housing plots area are surround by streets which are generally organized back-to-back(fig.5A). The roads are used to provide passage for cars, so they are wide with large open spaces with less shade the building and passengers(fig.5B) [26]. The layout does not look 
have architectural concept of three-dimensional and does not appear to carry any consideration of social customs, climatic conditions, orientation, economics, urban design and planning [27]. However, some areas have a higher status than others that are located to the corners of blocks or the house nearer to the main road.

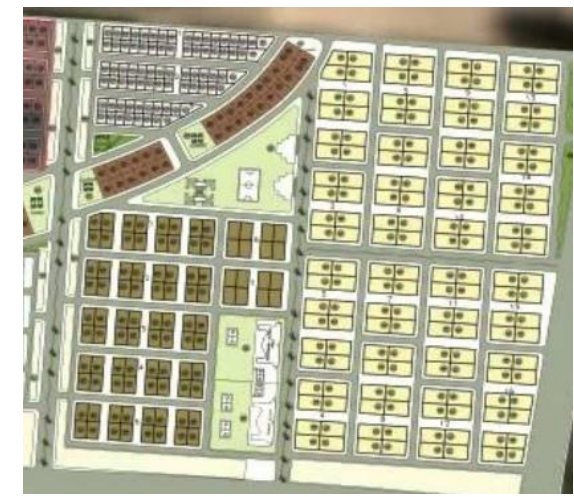

A- Site plan showing grid roads

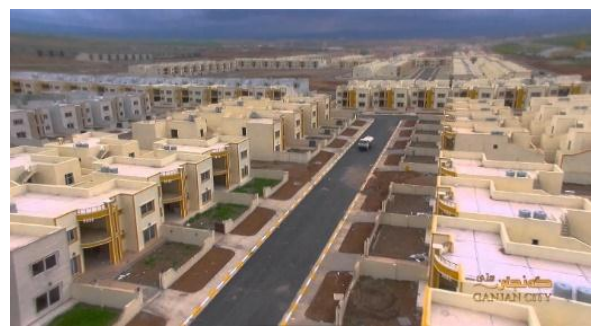

B-Aerial picture of residential building

Figure 5 Erbil city typical houses, Ganjan city Iraq, Erbil A-Site plan showing grid roads B-Aerial picture of residential building (www.Ganjancity.com)

\subsection{Form and Orientation}

Increasing of population and urban planning restrictions effected on Building form and the plot area of residential buildings, which were classified into variable size, small between $10 \mathrm{~m} * 15$ or20m (150-200 $\mathrm{m}^{2}$ ) which is widely used and built as terrace houses, medium $15 \mathrm{~m} * 20$ or $25 \mathrm{~m}\left(300-400 \mathrm{~m}^{2}\right)$ built as semidetached houses, large $20 \mathrm{~m} * 30$ or $40 \mathrm{~m}\left(600-800 \mathrm{~m}^{2}\right)$ are built as detached or semi-detached houses. The abovementioned factors made different plan form with a garden in the front, one and two stories or Multi-story (fig.6 A-B-D) [26]. The compactness of house apartment, terraced, semidetached, the houses do not protect and shade each other from rain in winter and sun radiation in summer (fig.6C), while the house orientation directed according to the distribution of urban planning without any attention to environmental consideration like wind exposer, solar access and heat loss and gain through the external envelop [28]. The house size in terms of the built area size, floor number and room number on each floor, which is related to the family and building plot size in addition to social and economic situation in the society [29].

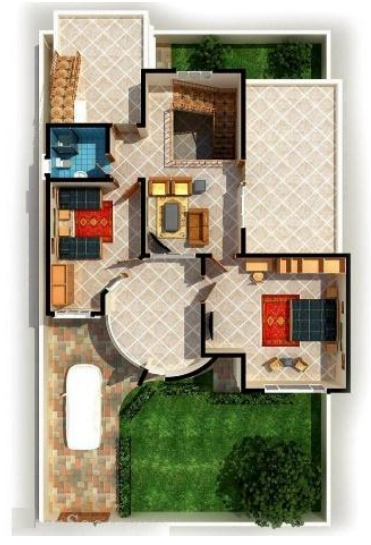

A- Ground Floor Plan

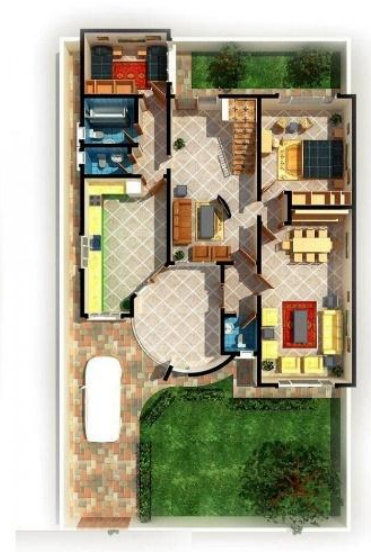

B-First Floor Plan

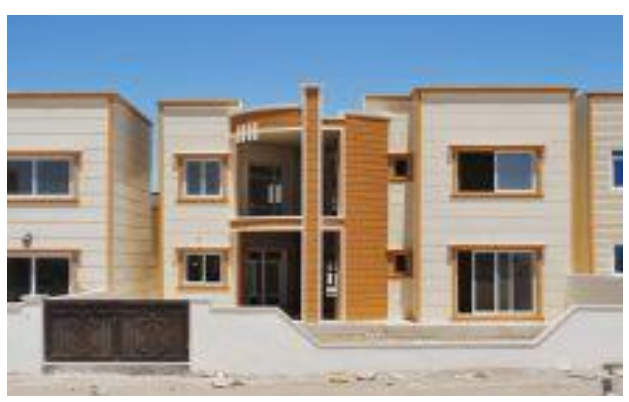

C- Elevation Plan

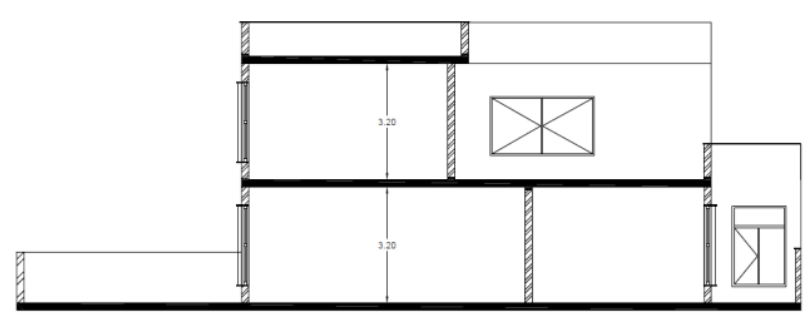

D- Section Plan (amperes)

Figure 6 Ganjan city typical houses A- Ground Floor Plan B-First Floor Plan C- Elevation Plan D- Section Plan (www.Ganjancity.com)

\subsection{Occupancy Migration- Plan Arrangement}

As many contemporary houses are comprised of apartments, terraced and semidetached (three sides) house generally designed free plan with a specific function for each zone or space, the occupants were forced to carry out their actions in specific areas, irrespective of the seasonal and daily changes in climate conditions. Those make the zone thermally uncomfortable by overheating in summer and cooling in winter, generally, the rooms look out-wards toward the garden or the street (the passage wayside) [30]. The plan arrangement has different types but generally ground floor include reception living room (Hall), kitchen room in the front house near to entrance and one or two 
bedrooms' in the behand while first floor include the rest of the bedrooms, these spaces are used throughout the year.

\subsection{Windows, Ventilation and Shading}

The external windows which oriented toward the street and front garden of ground floor (living, kitchen and reception) are large and first floor (bedrooms) are medium to large according to window to wall ratio, while the inside windows oriented to the shaft for lighting "minwar". This has no relationship with the seasonal specialization and environmental or geographical orientation. Therefore, the house cannot get advantage from such windows to encourage desirable heat gain in winter and avoid undesirable heat gain in summer. It is hard to decide the size of window for the room used during all seasons. the large windows in hot and dry reign cause overheating in summer and may by cooling in the winter by heat loss, therefor to achieve thermal comfort need device (air-condition) [31].

The external windows partially shaded by projecting small or large balconies "Tarma" of the first floor or by continuous horizontal straight overhangs, but these shading devices are there for rain protection and decorative purpose, without any relation to the orientation and sun angles in winter and summer. Most contemporary house have sufficient lighting due to the large windows while the ventilation is not functioned well because it not oriented to the correct wind breeze for the reasons previously mentioned and building Outward-looking [32].

\subsection{Water Body and Vegetation}

In fact, the garden in contemporary house is formed due to urban planning regulation, which forced the house to get away from the street 4 meters and have no relationship with climatic consideration. The garden located in the front of house include many kind of Vegetation, this cannot be cooling the inside temperature like courtyard because of its location and purpose which used the plants for decoration with neglecting the solar accesses and wind exposer. In the recent year, many houses removed his garden because they thought it useless [33].

Water bodies are not used in contemporary house because there is not enough space in the garden, and if it exists, it is used only for aesthetic purposes. For this reason, the use of vegetation and water are ineffective to reducing temperature inside the house [33].

\subsection{Building (construction) Materials}

Contemporary house in Erbil used for the construction reinforced concrete, and concrete block for structure (baring wall system), the roof is constructed by reinforced concrete material with thickness about $15 \mathrm{~cm}$, sometime covered by Terrazzo and porcelain tile, mostly without finishing. The external and interior walls are built from

concrete block with thickness about $20 \mathrm{~cm}$ generally finished with cement plaster, paints and Marble [34]. Windows and doors made from aluminum, plastic, wood, glass and steel, while ceramic and porcelain tile for floor finishes. Material previously mentioned incorporated in heavy weight constructions. Generally, both exterior walls and roof does not have thermal insulation, and is not thick enough to provide in sufficient U-value (against heat loss) and time lag (against heat gain) to achieve thermal comfort in winter and summer [35].

\section{6- ANALYSIS ANA EVALUATION}

This section will be evaluating and analysis both traditional and contemporary houses in Erbil city, in term of climate response strategies aspect and thermal comfort table 1. This comparison and evaluation can covered majority of houses in the city not all due to the different building size, form and materials ...etc.

Table 1 Evolution and Comparison between Traditional and Contemporary houses

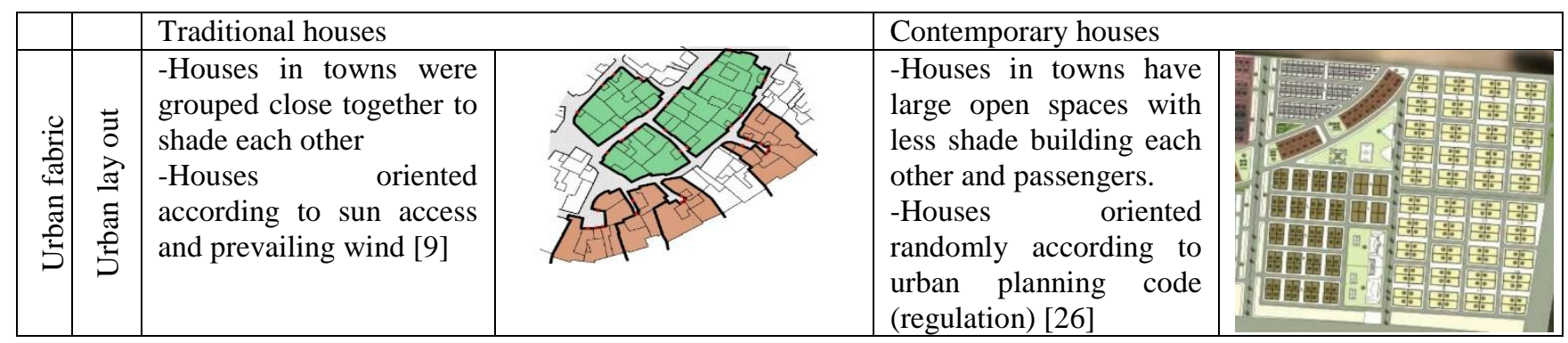




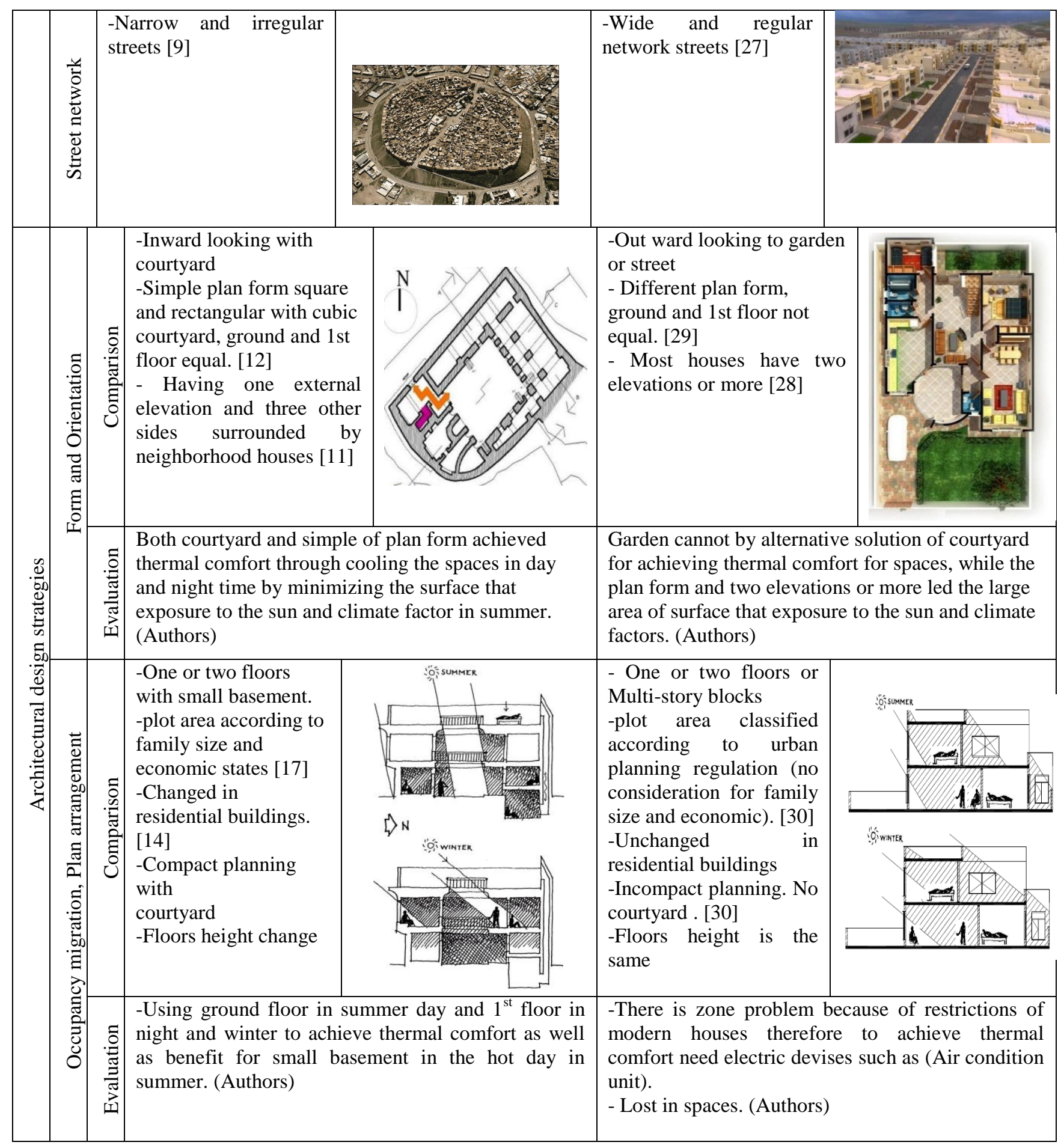




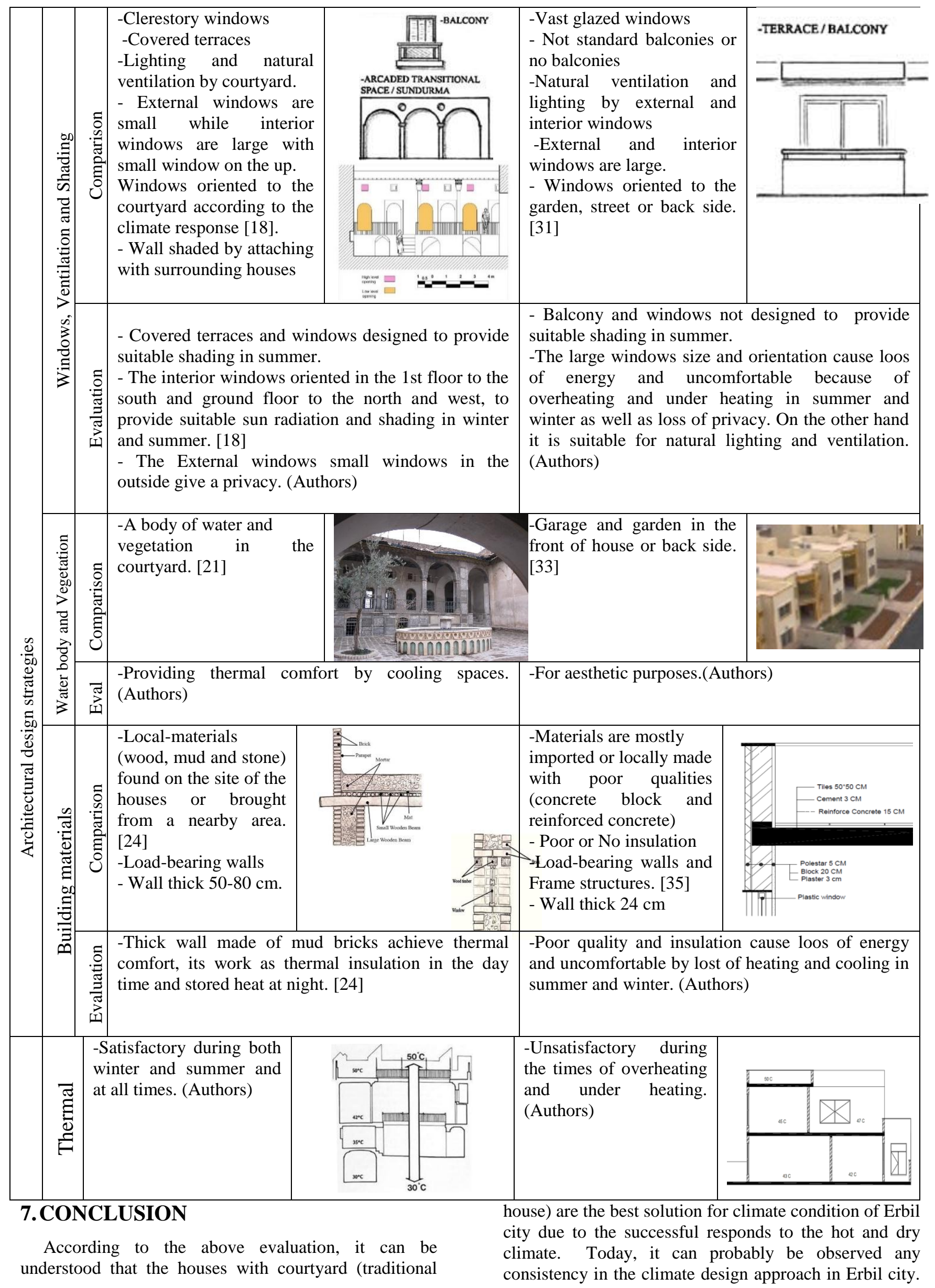


The micro- climatic factors such as sun access or orientation are ignored. The direction of wind breeze in many cases have not been taken in to consideration in building design, material selection and site planning, as well as the economic state (land prices, using chip marital) and increase population in the main towns this leading residential sector to be far away from the both urban and architectural quality. Thermal comfort and climatic design have been ignored by engineer and designers that cause utilizing of mechanical devise such as (Air-Condition unit) to control the thermal comfort in the house, that main massive wastage of money and energy resources.

Based on the above evaluation, May be the available climate design considerations can be addressed:

- Design of Landscape. Specially, to providing shade and cooling for spaces during the hotsummer times by the trees and Vegetation.

- Designing of semi-open and open spaces for example courtyards, balconies, terraces and verandas.

- Block concrete should be replaced by local material like stone, brick and preferred used new material and system

- prevailing wind direction and sun access or orientation should by Highly respected

- Utilizing suitable building element and shading device that provide climate solutions for instance sun devices, blinds and overhangs. PVS shutters

- with louvers are appropriate and available for Erbil climate.

- Using suitable thick of thermal insulating of walls and roof with suitable high of ceilings.

Utilizing light color to reflect the heat (sun radiation) such as white with pure form.

\section{REFERENCE}

[1] I. Basil, "Mega-project plans for developing the power and water sector in iraq and kurdistan region of iraq," UAE, Dubai, 2014.

[2] F. Hassan, "Architecture for the Poor : An Experiment in Rural Egypt Press", USA: University of Chicago, ISBN 0-226-23916-0, 1976.

[3] O. Nazife, "A comparative study of climatically responsive house design at various periods of Northern Cyprus architecture," Building and Environment, vol. 40, p. 841-852, 2005.

[4] A. Boqvist, et al., "Passive House Construction . What is the Difference Compared to Traditional Construction?," The Open Construction and Building Technology Journal, vol. 4, pp. 9-16, 2012.
[5] KRG, "Kurdistan's geography and climate," 2017. [Online]. Available: http://www.gov.krd/p/p.aspx?l=12\&p=213. [Accessed 117 2017].

[6] Y. A. Qusai and M. M. Lookman, , "Dust storm in Erbil city as a result of climatic change in Kurdistan Region Iraq," in Iraqi Journal of Science, Baghdad, 2012.

[7] B. Singh, "Building in Hot Dry Climates", USA: John Wiley, 1980.

[8] F. W. Al-Hashimi, "The Persistent Element in the Old Urban Fabric, Erbil Bazar Area," Journal of Strategic Innovation and Sustainability, vol. 10, no. 2, pp. 48-57, 2015.

[9] B. Givoni, L. Orlick, "Planning for Comfort in Hot Dry Climatic Regions," GeoJournal, vol. 4, pp. 6080, 2000.

[10] N. Hoshiar, "Architectural Identity in an Era of Change," Developing Country Studies, vol. 2, no. 2224-607X, pp. 81-96, No.10, 2012.

[11] A. Fazia and M. Helmut, "Numerical Study on the Effects of Aspect Ratio and Orientation of an Urban Street Canyon on Outdoor Thermal Comfort in Hot and Dry Climate," Building and Environment, vol. 41, no. 2, pp. 94-108, 2006.

[12] M. Mustafa and Y. Hong, "The Characteristics of Architecture Style of the Traditional Houses in the Mosul City," American journal of Engineering and Applied Sciences, vol. 3, no. 2, 2010.

[13] S. H. Al-Azzawi, "A Descriptive, Analytical and Comparative Study of Traditional Courtyard Houses and Modern Non-Courtyard Houses in Baghdad: (in the Context of Urban Design in the Hot-Dry Climates of the Sub-Tropics) ". University of London, London,", 1984.

[14] S. H. Al-Azzawi, "Seasonal impact of climate on the pattern of urban family life," Renewable Energy, vol. 8, no. 1, pp. 283-288, 1996.

[15] J. Warren and F. Ihsan, "Traditional Houses in Baghdad, " vol. 1, England: Coach Pub House, 1982.

[16] H. A. Abdulkareem, "Thermal comfort through the microclimates of the courtyard. A critical review of the middle-eastern courtyard house as a climatic response," Procedia - Social and Behavioral Sciences, vol. 216, p. 662 - 674, 2016.

[17] M. A. Kamal and T. A. Shelab, "Sustainability through Natural Cooling: Bioclimatic Design and Traditional Architecture," Study of Civil Engineering and Architecture, vol. 3, pp. 1-6, 2014.

[18] A. Aflaki, et al. "A review on natural ventilation applications through building façade components and ventilation openings in tropical climates," Energy and Buildings, vol. 101, pp. 153-162., 2015.

[19] M. Bahramzadeh, et al., "A Comparative Study to Compare the Wind Catcher Types in the Architecture of Islamic Countries," Journal of Basic 
and Applied Scientific Research, vol. 3, no. 2, pp. 312-316, 2015.

[20] B. Edwards, "Courtyard Housing: Past, Present and Future, " London: Taylor and Francis, 2006.

[21] A. Shady, "The role of landscape design in improving the microclimate in traditional courtyard-buildings in hot arid climates," in The 23rd Conference on Passive and Low Energy Architecture, Geneva, Switzerland. Université de Genève, 2006.

[22] H. V. Elham and A. Masoome, "Impact of Hot and Arid Climate on Architecture (Case Study: Varzaneh)," Procedia Engineering, vol. 94, pp. 2532, 2014.

[23] B. Sigalit, et al., "Study of Thermal Comfort in Courtyards in a Hot Arid Climate," Solar Energy, vol. 86, no. 5, pp. 1173-1186, 2012.

[24] M. Dabaieh and O. Wanas, "Reducing cooling demands in a hot dry climate: A simulation study for non-insulated passive cool roof thermal performance in residential buildings," Energy and Buildings, vol. 89, pp. 142-152, 2015.

[25] A. Almusaed and A. Almssad, "Building materials in eco-energy houses from Iraq and Iran," Case Studies in Construction Materials, vol. 2, pp. 42-54, 2015.

[26] D. A. Dar-Alhandasah, "Erbil City Master Plan Report, Directorate of Research \& Studies-General Directorate of Constructive Planning," Ministry of Municipalities/Kurdistan Regional Government, Erbil, 2007.

[27] A. Levy, "Urban morphology and the problem of the modern urban fabric: some questions for research," Urban Morphology, vol. 3, no. 2, pp. 79$85,1999$.

[28] K. Al-Kodmany, "Residential visual privacy: Traditional and modern architecture and urban design," Journal of Urban Design, vol. 4, no. 3, pp. 283-311, 1999.

[29] A. H. Al-Jameel and H. H. Kasim, "ReImplementation of Courtyard in Modern House Architecture in Iraq," Istanbul, Turkey, 2016.

[30] A. Al-Thahab, et al., "Between Tradition and Modernity: Determining Spatial Systems of Privacy in the Domestic Architecture of Contemporary Iraq," International Journal of Architectural Research, vol. 8, no. 3, pp. 238-250, 2014.

[31] Y. B. Salahaddin and S. H. Ahmad, "The Influence of Modernity on Kurdish Architectural Identity," American J. of Engineering and Applied Sciences, vol. 3, no. 1941-7020, pp. 52-559, 2010.

[32] D. M. Rostam, "Evolved Sustainable Building Engineering in Vernacular Architecture of Kurdistan," ARO-The Scientific Journal of Koya University, vol. 1, pp. 9-19, 2017.

[33] Y. Salahaddin, et al. "Modrenization Theory and House Garden Transformation case study Erbil city," ARO-The Scientific Journal of Koya University, no. 2307-549X, pp. 8-13, 2013,.

[34] D. M. Rostam, et al. "Economical and Structural Feasibility of Concrete Cellular and Solid Blocks in Kurdistan Region," ARO-The Scientific Journal of Koya University, vol. 4, no. 1, pp. 1-7, 2016.

[35] A. Utama and S. H. Gheewala, "Influence of material selection on energy demand in residential houses," The Journal of Material and Design:Elsevier, 2009. 